Review

\title{
Incremental value of the measures of arterial stiffness in cardiovascular risk assessment
}

\author{
Gwon Pung Lee ${ }^{1}$, Hack-Lyoung Kim ${ }^{1}$ * \\ ${ }^{1}$ Division of Cardiology, Department of Internal Medicine, Boramae Medical Center, Seoul National University College of Medicine, 07061 Seoul, \\ Republic of Korea \\ *Correspondence: kh12876@gmail.com (Hack-Lyoung Kim) \\ Academic Editor: Takatoshi Kasai \\ Submitted: 1 November 2021 Revised: 24 November 2021 Accepted: 1 December 2021 Published: 11 January 2022
}

\begin{abstract}
Predicting the occurrence of organ damage and future cardiovascular events is critical to improving patient prognosis through early personalized treatment. Although many tools have been developed and used for individuals' cardiovascular risk, they have limitations and unmet needs for improved risk stratification. For this purpose, arterial stiffness information can be practical. Arterial walls stiffen with age or prolonged exposure to various noxious stimuli such as high blood pressure, hyperglycemia, inflammation and oxidative stress. Differently from several methods of measuring arterial stiffness, pulse wave velocity (PWV) is most widely used for its noninvasive and easy measurement. It is well authorized that information on arterial stiffness is associated with the development of future cardiovascular events, independent from traditional cardiovascular risk factors, in various patient groups with specific diseases along with the general population. Moreover, when this information of arterial stiffness is associated with other risk stratification tools, it is possible to predict individuals' cardiovascular risk easier. Herein, we will review the incremental value of the measurement of arterial stiffness in cardiovascular risk assessment when combined with other risk factors such as traditional risk factors, biomarkers, other vascular testing and non-invasive cardiac imaging.
\end{abstract}

Keywords: Arterial stiffness; Cardiovascular risk; Incremental value; Pulse wave velocity; Risk assessment

\section{Introduction}

Cardiovascular disease (CVD) is the leading cause of death and morbidity worldwide [1,2]. To improve the cardiovascular prognosis, it is essential to earlier detect highrisk individuals and provide the individualized treatment [3]. To do this, an appropriate method must be in place to assess individuals' risk. The most common way to predict cardiovascular risk is to identify traditional risk factors [48]. However, it has been reported that a substantial portion of individuals without conventional risk factors have experienced cardiovascular events [9]. Although several cardiovascular risk scores have been obtained based on the combination of these traditional risk factors and utilized for risk prediction $[3,10]$, these risk scores are difficult to apply to Asians because they are computed based on the results of a study mainly targeting people in Western countries [11]. Cardiac biomarkers, such as C-reactive protein, natriuretic peptide, and troponin, are also helpful in risk classification; however, it requires considerable effort in methodology and some of which need more validation [12]. Non-invasive cardiac imaging tools, such as echocardiography, myocardial perfusion imaging (MPI) and coronary computed tomography angiography (CCTA), have high power for predicting future cardiovascular events, but these tests need cost and time and have side effects such as radiation exposure and nephrotoxicity $[13,14]$.

Recently, interest in arterial stiffness in the cardiovas- cular field has been increasing. Artery stiffened with age or prolonged exposure to various noxious stimuli such as high blood pressure, hyperglycemia, inflammation, and oxidative stress [15-17]. There are various methods to measure arterial stiffness [17] and these measurements are useful for predicting cardiovascular risk [18,19]. Many studies have shown that the information of arterial stiffness was significantly associated with the occurrence of future cardiovascular events not only in the general population but also in patients with various diseases, even when confounding effects of multiple cardiovascular risk factors were adjusted [20-26]. Of note, it has been suggested that arterial stiffness information has additional value when used simultaneously with other risk stratification tools. Through this method, the prognostic value of arterial stiffness can be applied more effectively. Herein, the incremental value of the measures of arterial stiffness in cardiovascular risk assessment will be reviewed.

\section{Measures of arterial stiffness}

There are various measures of arterial stiffness such as pulse pressure (PP), pulse wave velocity (PWV) and augmentation index (AIx) [15-17,27]. These values can be obtained both non-invasively and invasively. Although invasive measurement of intra-arterial hemodynamic profiles by catheterization is the most accurate method, its use is hindered by invasiveness, cost, and time. Therefore, inva- 
sive methods are used for validation purpose [28,29]. However, in patients undergoing invasive coronary angiography (CAG), invasive aortic pressure measurement is feasible without additional risk and cost; some studies have reported the usefulness of this measurement [28-32]. In other situations, most measures of arterial stiffness can be obtained by non-invasive methods. Given that the transmission speed of pulse wave passing through the arterial wall (pulse wave velocity, PWV) is proportional to the degree of arterial stiffness, the PWV is a direct and reliable measure of arterial stiffness $[16,17,33,34]$. The PWV can be simply obtained by dividing distance by the difference in the arrival time of the waveforms between the two different arterial points [17]. There are several types of PWV, depending on the location of the artery being measured. Among them, carotidfemoral PWV (cfPWV) and brachial-ankle PWV (baPWV) are the most widely used [34]. PP and AIx are also important indicators of arterial stiffness. As the velocity and amplitude of reflected waves in stiffened arteries increases, it merges earlier with forwarding waves, leading to increase AIx (the amount of pressure augmentation relative to PP) and PP [27]. Because of simplicity and generous clinical data, PWV has been the most widely used among various measures of arterial stiffness [17,33]. PWV can be measured non-invasively with commercially available equipment. Echocardiography, computed tomography, and magnetic resonance imaging are also applied to measure arterial stiffness. There are several different methods for measuring arterial stiffness using these imaging techniques, but the method of calculating aortic distensibility based on the change in the size of the aorta during systolic and diastole is mainly used [15]. However, they are only used for research purposes due to cost and technical issues.

\section{Prognostic value of the measures of arterial stiffness}

The most important clinical value of information on arterial stiffness is that it is associated with future cardiovascular events and we can use it in risk assessment. In a study that followed 2232 participants in the Framingham Heart Study cohort for 7.8 years, higher aortic PWV was associated with a $48 \%$ increase in cardiovascular disease risk in multivariable analysis [24]. In a 9.4-year follow-up study of 1678 general Danish peoples, for each 1 SD increase in $\operatorname{cfPWV}(3.4 \mathrm{~m} / \mathrm{s})$, there was a $16 \%-20 \%$ increase in the development of coronary artery disease (CAD), which was significant even after adjusting for several clinical factors [21]. Kim et al. [35] investigated 2561 hypertensive subjects and showed that higher baPWV $(\geq 1630 \mathrm{~cm} / \mathrm{s})$ was independently associated with a higher risk of the occurrence of cardiovascular events during a median follow-up period of 4.14 years. Other studies have also shown similar results of the prognostic value of PWV in hypertensive and diabetic patients $[25,26,36,37]$. In CAD patients, increased arterial stiffness was associated with future development of mortal- ity and cardiovascular events $[22,38,39]$. In a recent study, both invasive and non-invasive measurements of PWV values in patients undergoing invasive CAG were all significant factors associated with the occurrence of coronary events [22]. Ki et al. [38] investigated 372 patients who underwent percutaneous coronary intervention (PCI), and demonstrated that a higher baseline baPWV value $(\geq 1672$ $\mathrm{cm} / \mathrm{s}$ ) is a predictive marker for cardiac death after PCI. A higher baseline baPWV value was an independent factor predicting mortality and functional outcome in patients with acute stroke [23,40,41]. In a cohort of 241 patients with end-stage renal disease (ESRD) undergoing hemodialysis, each aortic PWV increase of $1 \mathrm{~m} / \mathrm{s}$ was associated with a 1.4-fold increase in mortality during 72 months of clinical follow-up [42]. Other studies have also reported that the increase in arterial stiffness in chronic kidney disease (CKD) patients is an essential factor determining patients' cardiovascular prognosis $[43,44]$. The measures of arterial stiffness are also practical in predicting clinical outcomes in patients with heart failure $[45,46]$. In meta-analyses, both aortic PWV and baPWV are predictors of future cardiovascular events in various patient populations: every $1 \mathrm{SD}$ increase in the aortic PWV and baPWV were associated with $47 \%$ and $19 \%$ increase respectively, in the risk of CVD $[18,19]$. Collectively, in the general population as well as in patients with various diseases, increased arterial stiffness was associated with increased cardiovascular risk. Based on the clinical usefulness of this arterial stiffness measurement information, European and Japanese guidelines recommend cfPWV and baPWV measurements, respectively, for risk assessment in hypertensive patients $[47,48]$.

\section{Pathophysiology}

The mechanism by which increased arterial stiffness induces cardiovascular disease can be explained as follows. In stiffened artery, the transmission speed of the pulse wave moving along the arterial wall increases so that the reflected wave is combined with the forward wave at early stages, leading to systolic augmentation [27]. This further raises systolic blood pressure and lowers diastolic blood pressure. Increased systolic and pulse pressures cause left ventricular hypertrophy, which promotes left ventricular diastolic dysfunction and subendocardial ischemia [49]. Reduction in diastolic blood pressure in the stiffened aorta lowers coronary blood flow, further promoting myocardial ischemia [50,51]. Increased pulsatile nature of arterial pressure by arterial stiffening promotes the influx of lipids into the subendothelial layer, plaque progression, and weakening of fibrous cap, which leads to plaque rupture $[52,53]$. The increase in PP accelerates carotid artery atherosclerosis and cerebral small vessel damage [54,55]. Shared risk factors (high blood pressure, hyperglycemia, dyslipidemia, smoking, inflammation, endothelial cell dysfunction oxidative stress, etc.) between increased arterial stiffness and cardiovascular disease may be another important pathophysiology 


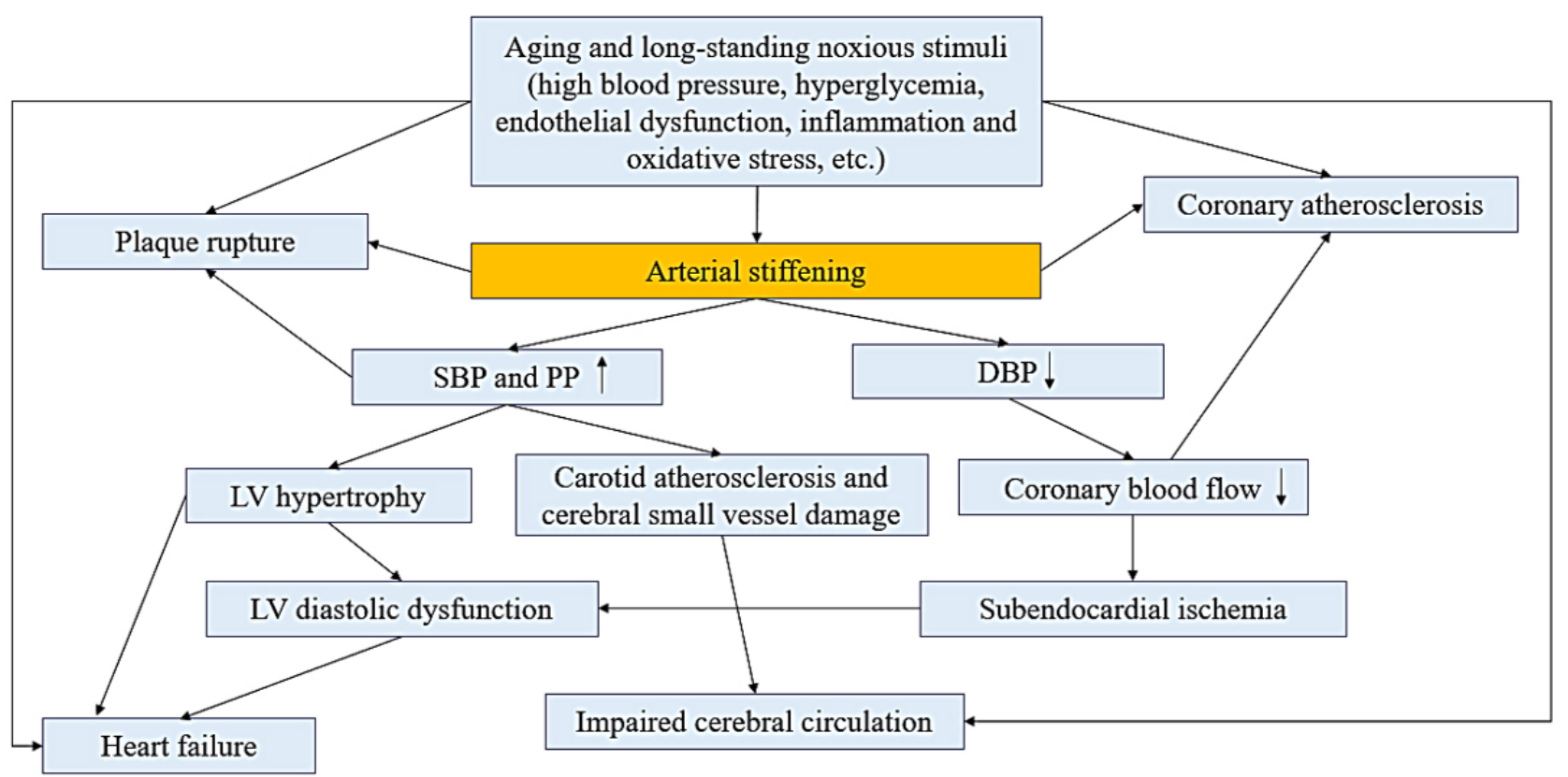

Fig. 1. Pathophysiology in the association of arterial stiffness with organ damage and the development of cardiovascular events. SBP, systolic blood pressure; PP, pulse pressure; DBP, diastolic blood pressure; LV, left ventricle; BBB, blood-brain barrier.

$[33,34]$. Possible underlying pathophysiology in the association of arterial stiffness with organ damage and the development of cardiovascular events is demonstrated in Fig. 1.

\section{Incremental value of the measures of arterial stiffness in detecting of CAD}

Using the information on arterial stiffness can help detect CAD. Wang et al. [56] demonstrated that carotid wall elastic modulus measured by shear wave elastography had incremental value in identifying obstructive CAD to clinical risk factors and other parameters. In that study, when carotid elasticity information was added to Framingham risk factor, ankle-brachial index, and global cardiac calcium score, the probability of detecting obstructive CAD was significantly increased (overall Chi-square, 9.95 to 15.86). It has been reported that the combination of increased cfPWV had incremental predictive value to other risk factors for the detection of impaired coronary flow reserve (CFR) [57,58]. Tzortzis et al. [57] investigated 110 untreated hypertensive patients and reported that patients with carotid intima-media thickness (IMT) $>1 \mathrm{~mm}$, cfPWV $>10.2 \mathrm{~m} / \mathrm{s}$ or their combination had an odds ratio of 3.5, 5.0 and 11.2, respectively for a CFR $<2.5$. The same study group also demonstrated that cfPWV had incremental value in the determination of CFR when added to traditional risk factors and echocardiographic parameters [58]. In a study of 233 patients with myocardial ischemia, adding information on baPWV to myocardial perfusion imaging (MPI) results and clinical parameters significantly increased diagnostic accuracy in the detection of obstructive $\mathrm{CAD}$ in patients with mild ischemia, but not in those with moderate or severe is- chemia on MPI [59]. This implies that baPWV may be more valuable with MPI for the detection of obstructive CAD, especially in patients with mild ischemia on MPI.

\section{Incremental prognostic value of the measures of arterial stiffness}

Kaolawanich et al. [60] investigated 520 patients who underwent adenosine stress cardiac magnetic resonance (CMR) and demonstrated that aortic PWV measured by $\mathrm{CMR}$ had incremental prognostic value to $\mathrm{CMR}$ results in the prediction of cardiovascular (CV) events during the median follow-up period of 46.5 months. In that study, patients with a higher PWV and positive ischemia on CMR had a significantly higher event rate compared to those with a lower PWV and negative ischemia (HR [hazard ratio], 8.94; $p<0.001$ ). In a study that analyzed 350 patients with suspected CAD who underwent MPI, when baPWV information was added to traditional risk factors and the MPI results, the occurrence of cardiovascular events was predicted better (overall Chi-square, from 24.08 to $27.42 ; p<0.001$ ) [61]. Hwang et al. [62] looked at 523 patients with suspected CAD and reported that the addition of baPWV to clinical factors and CCTA findings significantly improved the prediction of cardiovascular events (overall Chi-square, 132 to $154 ; p=0.005)$. In a study that followed 382 patients with acute coronary syndrome (ACS) (median follow-up period of 62 months), the addition of cardio-ankle vascular index (CAVI) to the GRACE risk score enhanced net reclassification improvement (NRI) and integrated discrimination improvement (IDI) (NRI, 0.337, $p=0.034$; IDI, $0.028, p=0.004$ ) [63]. In 2232 participants in the Fram- 


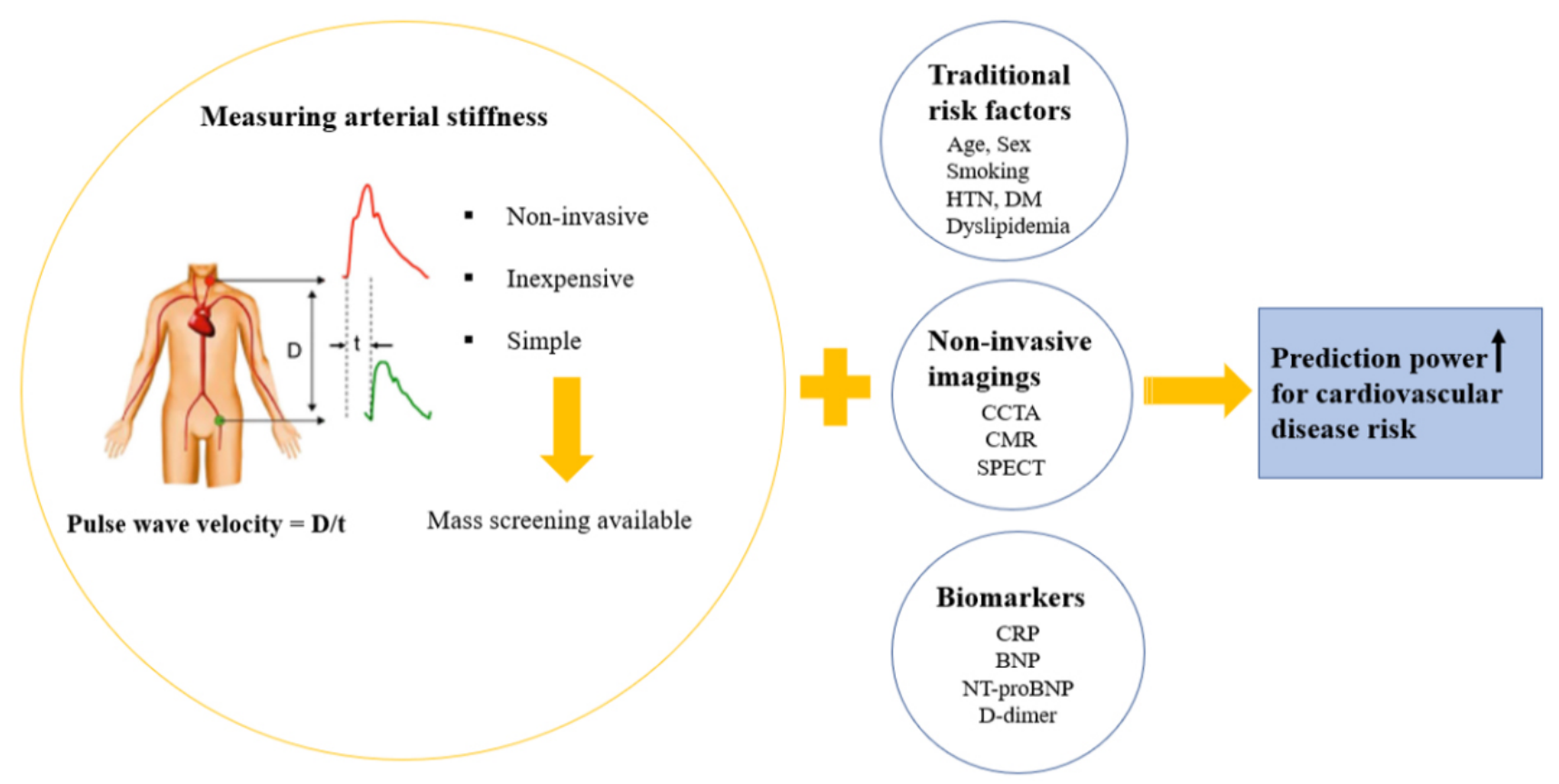

Fig. 2. Clinical use of the measures of arterial stiffness to increase prediction of cardiovascular prognosis. $D$, distance; $t$, time; HTN, hypertension; DM, diabetes mellitus; CCTA, coronary computed tomography angiography; CMR, cardiac magnetic resonance; SPECT, single position emission computed tomography; CRP, C-reactive protein; BNP, Brain natriuretic peptide; NT-proBNP, N-terminal pro-B-type natriuretic peptide.

ingham Heart Study, cfPWV significantly improved risk prediction for the occurrence of $\mathrm{CV}$ events when added to standard risk factors [24]. Both flow-mediated dilation (FMD) and baPWV increased prognostic value in CAD patients [64-66]. For an example, in a multi-center study performed in Japan, although both baPWV (for baPWV $>1731$ $\mathrm{cm} / \mathrm{s}:$ HR, $1.86 ; 95 \%$ CI [confidence interval], 1.01-3.44) and FMD (for FMD >7.1\%: HR, 0.27; 95\% CI, 0.060.74 ) were associated with the future occurrence of coronary events of patients with stable CAD $(n=462$, median follow-up period of 49.2 months), when the information from these two tests combined together, the predictive power of the patient was further improved (HR, 6.84; 95\% CI, 1.84-44.31) [64]. Narayan et al. [67] analyzed the central arterial pressure waveforms of 838 elderly hypertensive patients and showed that when pressure time constants, an index of arterial stiffness, was added to the traditional cardiovascular risk factors, the predictive power of future $\mathrm{CV}$ events increased significantly. Similarly, in another study, the predictive power of future CVD was increased when information on multiple atherosclerotic indicators obtained from the analysis of central arterial pressure waveforms obtained from existing CV risk factors [68]. When cfPWV and CKD information were used simultaneously, the predictive power of long-term cardiovascular events increased in hypertensive patients [69]. A recent study reported that baPWV provided additional prognostic value in combination with clinical variables and high-sensitivity $\mathrm{C}$-reactive protein (hs-CRP) in predicting CVD in patients with CV risk factors (overall Chi-square score, 126 to $167, p<$ 0.001) [70]. Another study showed that the use of combined information of baPWV and ankle-brachial index (ABI) provides increased value in the prognosis of $\mathrm{CV}$ events in patients with acute myocardial infarction [71]. Studies showing incremental prognostic value of the measures of arterial stiffness are summarized in Table 1 (Ref. [24,60-67,6971]).

\section{Clinical implications}

Cardiovascular risk stratification is very important to provide individualized treatment appropriately, leading to improved prognosis [3]. Risk scores calculated using traditional risk factors, non-invasive imaging tests, and functional tests have been used to predict subjects' risk. However, even with these various methods, risk prediction was not satisfactory, and unmet needs remained. To be more specific, currently used cardiovascular risk scoring systems are Western-oriented, so it is not suitable for Asians [11], various imaging tests require expensive equipment, and there are concerns about radiation and radiocontrast toxicities $[13,14]$. In consideration of these points, there has been much interest in vascular function tests to predict the $\mathrm{CV}$ risk. In particular, PWV is the most widely used method for measuring arterial stiffness because it is non-invasive and simple to measure [15-17,33,34]. Arterial stiffness information itself has a high prognostic value in predicting the occurrence of future CVD in patients regardless of traditional risk factors. Many studies have proven this point 
Table 1. Summary of the studies showing incremental prognostic value of the measures of arterial stiffness.

\begin{tabular}{|c|c|c|c|c|c|}
\hline$\overline{\text { Source (year) }}$ & Population & $\begin{array}{l}\text { Number of subjects } \\
\text { (follow-up duration) }\end{array}$ & Clinical outcome evaluated & $\begin{array}{l}\text { Measure of arterial } \\
\text { stiffness }\end{array}$ & Summary of main finding \\
\hline$\overline{\text { Kim et al. (2021) [70] }}$ & Subjects with CV risk factors & 6572 (mean 3.75 years) & $\begin{array}{l}\text { CV death, AMI, coronary } \\
\text { revasc. and stroke }\end{array}$ & baPWV & $\begin{array}{l}\text { The combination of hs-CRP and baPWV provided a better prediction of } \\
\text { future CVD than either one by itself }(\mathrm{HR}, 7.08 ; p<0.001)\end{array}$ \\
\hline Park et al. (2020) [71] & Patients with AMI & 889 (mean 348 days) & $\begin{array}{l}\text { Cardiac death, AMI, PCI, HF } \\
\text { and stroke }\end{array}$ & baPWV & $\begin{array}{l}\text { Adding baPWV to ABI increases the prognostic power for } \mathrm{CV} \text { events (HR, } \\
\qquad 5.4 ; p=0.001) .\end{array}$ \\
\hline Maruhashi et al. (2018) [64] & Patients with CAD & 462 (median 49.2 months) & Coronary events & baPWV & $\begin{array}{l}\text { The combination of FMD and baPWV provides further risk stratification } \\
\text { for recurrent coronary events than does FMD alone or baPWV alone (HR, } \\
\qquad 7.07 ; p=0.002) .\end{array}$ \\
\hline Hwang et al. (2018) [62] & Patients with suspected CAD & 523 (median 43.9 months) & $\begin{array}{l}\mathrm{CV} \text { death, } \mathrm{AMI} \text {, coronary } \\
\text { revasc., stroke and } \\
\text { hospitalization for } \mathrm{CV} \text { causes }\end{array}$ & baPWV & $\begin{array}{l}\text { The addition of baPWV to clinical risk factors and CCTA findings } \\
\text { significantly improved the prediction of cardiovascular events (global } \\
\text { Chi-square score, from } 132 \text { to } 154 ; p=0.005 \text { ). }\end{array}$ \\
\hline$\overline{\text { Lee } \text { et al. (2015) [61] }}$ & Patients with suspected CAD & 350 (median 441 days) & $\begin{array}{l}\text { CV death, ACS and ischemic } \\
\text { stroke }\end{array}$ & baPWV & $\begin{array}{l}\text { High baPWV had incremental prognostic value to traditional risk factors } \\
\text { and abnormal MPI in predicting CV events (overall Chi-square score, from } \\
\qquad 24.08 \text { to } 27.42 ; p<0.001 \text { ). }\end{array}$ \\
\hline Sugamata et al. (2014) [66] & Patients with stable CAD & 923 (mean 64 months) & $\begin{array}{l}\text { Cardiac death, } \mathrm{AMI} \text { and } \mathrm{UA} \\
\text { requiring coronary revasc }\end{array}$ & baPWV & $\begin{array}{l}\text { The combined addition of FMD and baPWV to the risk assessment } \\
\text { algorithms significantly improved prognostic value in the prediction for CV } \\
\text { events (IDI, } 0.004 ; p<0.0001 \text { and NRI, } 0.47 ; p<0.0001 \text { ). }\end{array}$ \\
\hline Nagai et al. (2013) [65] & Elderly subjects & 274 (mean 41 months) & Vascular events & baPWV & $\begin{array}{l}\text { Both IMT and baPWV were taken into consideration, the efficacy } \\
\text { increased as compared with each test alone (HR, } 4.9 ; p=0.003 \text { ). }\end{array}$ \\
\hline$\overline{\text { Ohishi et al. (2011) [69] }}$ & Patients with hypertension & 531 (mean 7.0 years) & $\begin{array}{l}\text { Death, AMI, angina, HF and } \\
\text { stroke }\end{array}$ & cfPWV & $\begin{array}{c}\text { Combination of high cfPWV and CKD were independent predictors for } \\
\text { clinical events (HR, } 2.15 ; p=0.033) .\end{array}$ \\
\hline Mitchell et al. (2010) [24] & General population & 2232 (median 7.8 years) & AMI, UA, HF and stroke & cfPWV & $\begin{array}{c}\text { After cfPWV was added to a standard risk factor model, there was a } \\
\text { significant improvement in the prediction of } \mathrm{CV} \text { events (IDI, } 0.007 ; p< \\
0.05 \text { ). }\end{array}$ \\
\hline Kaolawanich, et al. (2020) [60 & ] Patients with suspected CAD & 520 (median 46.5 months) & $\begin{array}{l}\text { Mortality, ACS, HF, coronary } \\
\text { revasc. and stroke }\end{array}$ & $\begin{array}{l}\text { aPWV measured by } \\
\text { CMR }\end{array}$ & $\begin{array}{c}\text { Adding aortic stiffness to stress perfusion CMR could improve risk } \\
\text { assessment and prediction for future CV events (HR, } 2.41 ; p<0.001) \text {. }\end{array}$ \\
\hline Kirigaya, et al. (2020) [63] & Patients with ACS & 387 (median 62 months) & CV death, ACS, HF and stroke & CAVI & $\begin{array}{l}\text { For the incremental predictive value, the addition of CAVI to GRACE } \\
\text { score enhanced NRI }(0.337 ; p=0.034) \text { and IDI }(0.028 ; p=0.004) \text {. }\end{array}$ \\
\hline Narayan, et al. (2015) [67] & General population & 838 (mean 4.4 years) & AMI or stroke & $\begin{array}{l}\text { Systolic time constant } \\
\text { (carotid artery) }\end{array}$ & $\begin{array}{l}\text { Addition of systolic time constant to the Framingham Risk Score was } \\
\text { associated with an improvement in predictive accuracy for CV events (IDI, } \\
\qquad 0.0072 ; p=0.003 \text { and NRI, } 0.27 ; p=0.02 \text { ). }\end{array}$ \\
\hline
\end{tabular}


over the past several centuries $[18,19]$. As described in this review, several studies have recently reported that the measures of arterial stiffness have incremental value in the estimation of cardiovascular risk when it adds to traditional risk factors, non-invasive imaging tests or biomarkers [24,60$67,69-71]$. There is a limit to predicting individuals' cardiovascular risk with a single test, so combining the two test results can maximize its utility further. Considering this, clinicians and researchers will be able

to use arterial stiffness information more effectively. Additionally, arterial stiffness measurement is non-invasive, inexpensive and simple, which makes it more valuable for mass screening. However, it is important to remember that arterial stiffness information is not superior to the wellknown cardiovascular risk factors, but is more useful when used together [72]. Clinical use of the measures of arterial stiffness to increase prediction of cardiovascular prognosis with other risk factors is demonstrated in Fig. 2.

\section{Conclusions}

Information on arterial stiffness provides incremental value in addition to traditional cardiovascular risk factors, imaging tests and biomarkers which predict cardiovascular risk. In particular, PWV, the most widely used measure of arterial stiffness, is simple and non-invasive, so it will be useful for predicting cardiovascular risk in combination with other tests as a mass screening tool.

\section{Author contributions}

HLK created the overall flow and outline of this review article. GPL and HLK wrote the initial manuscript. HLK revised manuscript. All authors contributed to editorial changes in the manuscript. All authors read and approved the final manuscript.

\section{Ethics approval and consent to participate}

Not applicable.

\section{Acknowledgment}

Not applicable.

\section{Funding}

This research received no external funding.

\section{Conflict of interest}

The authors declare no conflict of interest. HackLyoung Kim is serving as one of the Guest editors of this journal. We declare that Hack-Lyoung Kim had no involvement in the peer review of this article and has no access to information regarding its peer review. Full responsibility for the editorial process for this article was delegated to Takatoshi Kasai.

\section{References}

[1] Virani SS, Alonso A, Aparicio HJ, Benjamin EJ, Bittencourt MS, Callaway CW, et al. Heart Disease and Stroke Statistics2021 Update: A Report from the American Heart Association. Circulation. 2021; 143: e254-e743.

[2] Weir HK, Anderson RN, Coleman King SM, Soman A, Thompson TD, Hong Y, et al. Heart Disease and Cancer Deaths Trends and Projections in the United States, 1969-2020. Preventing Chronic Disease. 2016; 13: E157.

[3] Arnett DK, Blumenthal RS, Albert MA, Buroker AB, Goldberger ZD, Hahn EJ, et al. 2019 ACC/AHA Guideline on the Primary Prevention of Cardiovascular Disease: A Report of the American College of Cardiology/American Heart Association Task Force on Clinical Practice Guidelines. Circulation. 2019; 140: e596-e646.

[4] Rao Kondapally Seshasai S, Kaptoge S, Thompson A, Di Angelantonio E, Gao P, Sarwar N, et al. Diabetes mellitus, fasting glucose, and risk of cause-specific death. The New England Journal of Medicine. 2011; 364: 829-841.

[5] Lewington S, Clarke R, Qizilbash N, Peto R, Collins R. Agespecific relevance of usual blood pressure to vascular mortality: a meta-analysis of individual data for one million adults in 61 prospective studies. The Lancet. 2002; 360: 1903-1913.

[6] Whitlock G, Lewington S, Sherliker P, Clarke R, Emberson J, Halsey J, et al. Body-mass index and cause-specific mortality in 900000 adults: collaborative analyses of 57 prospective studies. The Lancet. 2009; 373: 1083-1096.

[7] Lewington S, Whitlock G, Clarke R, Sherliker P, Emberson J, Halsey $\mathrm{J}$, et al. Blood cholesterol and vascular mortality by age, sex, and blood pressure: a meta-analysis of individual data from 61 prospective studies with 55,000 vascular deaths. The Lancet. 2007; 370: 1829-1839.

[8] Jha P, Ramasundarahettige C, Landsman V, Rostron B, Thun M, Anderson RN, et al. 21st-century hazards of smoking and benefits of cessation in the United States. The New England Journal of Medicine. 2013; 368: 341-350.

[9] Khot UN, Khot MB, Bajzer CT, Sapp SK, Ohman EM, Brener $\mathrm{SJ}$, et al. Prevalence of conventional risk factors in patients with coronary heart disease. The Journal of the American Medical Association. 2003; 290: 898-904.

[10] Conroy RM, Pyörälä K, Fitzgerald AP, Sans S, Menotti A, De Backer G, et al. Estimation of ten-year risk of fatal cardiovascular disease in Europe: the SCORE project. European Heart Journal. 2003; 24: 987-1003.

[11] Barzi F, Patel A, Gu D, Sritara P, Lam TH, Rodgers A, et al. Cardiovascular risk prediction tools for populations in Asia. Journal of Epidemiology and Community Health. 2007; 61: 115-121.

[12] Libby P, King K. Biomarkers: a Challenging Conundrum in Cardiovascular Disease. Arteriosclerosis, Thrombosis, and Vascular Biology. 2015; 35: 2491-2495.

[13] Newby DE, Adamson PD, Berry C, Boon NA, Dweck MR, Flather M, et al. Coronary CT Angiography and 5-Year Risk of Myocardial Infarction. New England Journal of Medicine. 2018; 379: 924-933.

[14] Hachamovitch R, Berman DS, Kiat H, Cohen I, Cabico JA, Friedman J, et al. Exercise myocardial perfusion SPECT in patients without known coronary artery disease: incremental prognostic value and use in risk stratification. Circulation. 1996; 93 : 905-914.

[15] Chirinos JA, Segers P, Hughes T, Townsend R. Large-Artery Stiffness in Health and Disease: JACC State-of-the-Art Review. Journal of the American College of Cardiology. 2019; 74: 1237 1263.

[16] Lee HY, Oh BH. Aging and arterial stiffness. Circulation Journal. 2010; 74: 2257-2262. 
[17] Cavalcante JL, Lima JA, Redheuil A, Al-Mallah MH. Aortic stiffness: current understanding and future directions. Journal of the American College of Cardiology. 2011; 57: 1511-1522.

[18] Vlachopoulos C, Aznaouridis K, Stefanadis C. Prediction of cardiovascular events and all-cause mortality with arterial stiffness: a systematic review and meta-analysis. Journal of the American College of Cardiology. 2010; 55: 1318-1327.

[19] Ohkuma T, Ninomiya T, Tomiyama H, Kario K, Hoshide S, Kita Y, et al. Brachial-Ankle Pulse Wave Velocity and the Risk Prediction of Cardiovascular Disease: an Individual Participant Data Meta-Analysis. Hypertension. 2017; 69: 1045-1052.

[20] Mattace-Raso FU, van der Cammen TJ, Hofman A, van Popele NM, Bos ML, Schalekamp MA, et al. Arterial stiffness and risk of coronary heart disease and stroke: the Rotterdam Study. Circulation. 2006; 113: 657-663.

[21] Willum-Hansen T, Staessen JA, Torp-Pedersen C, Rasmussen $\mathrm{S}$, Thijs L, Ibsen $\mathrm{H}$, et al. Prognostic value of aortic pulse wave velocity as index of arterial stiffness in the general population. Circulation. 2006; 113: 664-670.

[22] Hametner B, Wassertheurer S, Mayer CC, Danninger K, Binder RK, Weber T. Aortic Pulse Wave Velocity Predicts Cardiovascular Events and Mortality in Patients Undergoing Coronary Angiography: A Comparison of Invasive Measurements and Noninvasive Estimates. Hypertension. 2021; 77: 571-581.

[23] Ahn KT, Jeong JO, Jin SA, Kim M, Oh JK, Choi UL, et al. Brachial-ankle PWV for predicting clinical outcomes in patients with acute stroke. Blood Pressure. 2017; 26: 204-210.

[24] Mitchell GF, Hwang SJ, Vasan RS, Larson MG, Pencina MJ, Hamburg NM, et al. Arterial stiffness and cardiovascular events: the Framingham Heart Study. Circulation. 2010; 121: 505-511.

[25] Kim JM, Kim SS, Kim IJ, Kim JH, Kim BH, Kim MK, et al. Arterial stiffness is an independent predictor for risk of mortality in patients with type 2 diabetes mellitus: the REBOUND study. Cardiovascular Diabetology. 2020; 19: 143.

[26] Boutouyrie P, Tropeano AI, Asmar R, Gautier I, Benetos A, Lacolley $\mathrm{P}$, et al. Aortic stiffness is an independent predictor of primary coronary events in hypertensive patients: a longitudinal study. Hypertension. 2002; 39: 10-15.

[27] Weber T, Chirinos JA. Pulsatile arterial haemodynamics in heart failure. European Heart Journal. 2018; 39: 3847-3854.

[28] Kang J, Kim HL, Lim WH, Seo JB, Zo JH, Kim MA, et al. Relationship between brachial-ankle pulse wave velocity and invasively measured aortic pulse pressure. The Journal of Clinical Hypertension. 2018; 20: 462-468.

[29] Styczynski G, Rdzanek A, Pietrasik A, Kochman J, Huczek Z, Sobieraj P, et al. Echocardiographic Assessment of Aortic PulseWave Velocity: Validation against Invasive Pressure Measurements. Journal of the American Society of Echocardiography. 2016; 29: 1109-1116.

[30] Chung J, Kim HL, Lim WH, Seo JB, Kim SH, Zo JH, et al. Association between invasively measured aortic pulse pressure and orthostatic hypotension in patients undergoing invasive coronary angiography. Journal of Hypertension. 2019; 37: 19661973.

[31] Weber T, Auer J, O’Rourke MF, Kvas E, Lassnig E, Berent R, et al. Arterial stiffness, wave reflections, and the risk of coronary artery disease. Circulation. 2004; 109: 184-189.

[32] Kim KJ, Kim HL, Kim MJ, Kim CH, Lim WH, Seo JB, et al. Gender Difference in the Association between Aortic Pulse Pressure and Left Ventricular Filling Pressure in the Elderly: an Invasive Hemodynamic Study. Journal of Cardiac Failure. 2017; 23: 224-230.

[33] Laurent S, Cockcroft J, Van Bortel L, Boutouyrie P, Giannattasio C, Hayoz D, et al. Expert consensus document on arterial stiffness: methodological issues and clinical applications. European Heart Journal. 2006; 27: 2588-2605.
[34] Kim HL, Kim SH. Pulse Wave Velocity in Atherosclerosis. Frontiers in Cardiovascular Medicine. 2019; 6: 41.

[35] Kim HL, Lim WH, Seo JB, Kim SH, Zo ZH, Kim MA. Prediction of cardiovascular events using brachial $\square$ ankle pulse wave velocity in hypertensive patients. The Journal of Clinical Hypertension. 2020; 22: 1659-1665.

[36] Cruickshank K, Riste L, Anderson SG, Wright JS, Dunn G, Gosling RG. Aortic pulse-wave velocity and its relationship to mortality in diabetes and glucose intolerance: an integrated index of vascular function? Circulation. 2002; 106: 2085-2090.

[37] Katakami N, Osonoi T, Takahara M, Saitou M, Matsuoka TA, Yamasaki Y, et al. Clinical utility of brachial-ankle pulse wave velocity in the prediction of cardiovascular events in diabetic patients. Cardiovascular Diabetology. 2014; 13: 128.

[38] Ki YJ, Choi DH, Lee YM, Lim L, Song H, Koh YY. Predictive value of brachial-ankle pulse wave velocity for long-term clinical outcomes after percutaneous coronary intervention in a Korean cohort. International Journal of Cardiology. 2014; 175: 554-559.

[39] Tomiyama H, Koji Y, Yambe M, Shiina K, Motobe K, Yamada $\mathrm{J}$, et al. Brachial - ankle pulse wave velocity is a simple and independent predictor of prognosis in patients with acute coronary syndrome. Circulation Journal. 2005; 69: 815-822.

[40] Kim J, Song TJ, Kim EH, Lee KJ, Lee HS, Nam CM, et al. Brachial-Ankle Pulse Wave Velocity for Predicting Functional Outcome in Acute Stroke. Stroke. 2014; 45: 2305-2310.

[41] Kim J, Song TJ, Song D, Lee KJ, Kim EH, Lee HS, et al. Brachial-Ankle Pulse Wave Velocity is a Strong Predictor for Mortality in Patients with Acute Stroke. Hypertension. 2014; 64: 240-246.

[42] Blacher J, Guerin AP, Pannier B, Marchais SJ, Safar ME, London GM. Impact of aortic stiffness on survival in end-stage renal disease. Circulation. 1999; 99: 2434-2439.

[43] Sigrist MK, Taal MW, Bungay P, McIntyre CW. Progressive vascular calcification over 2 years is associated with arterial stiffening and increased mortality in patients with stages 4 and 5 chronic kidney disease. Clinical Journal of the American Society of Nephrology. 2007; 2: 1241-1248.

[44] Baumann M, Wassertheurer S, Suttmann Y, Burkhardt K, Heemann U. Aortic pulse wave velocity predicts mortality in chronic kidney disease stages 2-4. Journal of Hypertension. 2014; 32: 899-903.

[45] Zhou J, Wang Y, Feng Y, Chen X, Zhang Q. New indices of arterial stiffness correlate with disease severity and mid-term prognosis in acute decompensated heart failure. Internal and Emergency Medicine. 2021; 16: 661-668.

[46] Meguro T, Nagatomo Y, Nagae A, Seki C, Kondou N, Shibata M, et al. Elevated Arterial Stiffness Evaluated by Brachial-Ankle Pulse Wave Velocity is Deleterious for the Prognosis of Patients with Heart Failure. Circulation Journal. 2009; 73: 673-680.

[47] Williams B, Mancia G, Spiering W, Agabiti Rosei E, Azizi M, Burnier M, et al. 2018 ESC/ESH Guidelines for the management of arterial hypertension. European Heart Journal. 2018; 39: 3021-3104.

[48] Umemura S, Arima H, Arima S, Asayama K, Dohi Y, Hirooka $\mathrm{Y}$, et al. The Japanese Society of Hypertension Guidelines for the Management of Hypertension (JSH 2019). Hypertension Research. 2019; 42: 1235-1481.

[49] Dart AM, Kingwell BA. Pulse pressure-a review of mechanisms and clinical relevance. Journal of the American College of Cardiology. 2001; 37: 975-984.

[50] Leung MC, Meredith IT, Cameron JD. Aortic stiffness affects the coronary blood flow response to percutaneous coronary intervention. American Journal of Physiology-Heart and Circulatory Physiology. 2006; 290: H624-H630.

[51] Nelson AJ, Puri R, Nicholls SJ, Dundon BK, Richardson JD, 
Sidharta SL, et al. Aortic distensibility is associated with both resting and hyperemic coronary blood flow. American Journal of Physiology-Heart and Circulatory Physiology. 2019; 317: $\mathrm{H} 811-\mathrm{H} 819$.

[52] Kiefer CR, McKenney JB, Trainor JF, Snyder LM. Pulsepressure-driven neutral lipid accumulation and correlative proinflammatory markers of accelerated atherogenesis. Atherosclerosis. 2005 ; 183: 17-24.

[53] Lee RT, Schoen FJ, Loree HM, Lark MW, Libby P. Circumferential stress and matrix metalloproteinase 1 in human coronary atherosclerosis. Implications for plaque rupture. Arteriosclerosis, Thrombosis, and Vascular Biology. 1996; 16: 1070-1073.

[54] Vigen T, Ihle $\square$ Hansen H, Lyngbakken MN, Berge T, Thommessen B, Ihle $\square$ Hansen $\mathrm{H}$, et al. Carotid Atherosclerosis is Associated with Middle Cerebral Artery Pulsatility Index. Journal of Neuroimaging. 2020; 30: 233-239.

[55] Zhai FF, Ye YC, Chen SY, Ding FM, Han F, Yang XL, et al. Arterial stiffness and cerebral small vessel disease. Frontiers in Neurology. 2018; 9: 723.

[56] Wang Y, Zhao C, Meng P, Yu Y, Li G, Kong F, et al. Incremental value of carotid elasticity modulus using shear wave elastography for identifying coronary artery disease in patients without carotid plaque. Journal of Hypertension. 2021; 39: 1210-1220.

[57] Tzortzis S, Ikonomidis I, Lekakis J, Papadopoulos C, Triantafyllidi $\mathrm{H}$, Parissis J, et al. Incremental predictive value of carotid intima-media thickness to arterial stiffness for impaired coronary flow reserve in untreated hypertensives. Hypertension Research. 2010; 33: 367-373.

[58] Ikonomidis I, Lekakis J, Papadopoulos C, Triantafyllidi H, Paraskevaidis I, Georgoula G, et al. Incremental value of pulse wave velocity in the determination of coronary microcirculatory dysfunction in never-treated patients with essential hypertension. American Journal of Hypertension. 2008; 21: 806-813.

[59] Jang K, Kim HL, Park M, Oh S, Oh SW, Lim WH, et al. Additional Value of Brachial-Ankle Pulse Wave Velocity to Single-Photon Emission Computed Tomography in the Diagnosis of Coronary Artery Disease. Journal of Atherosclerosis and Thrombosis. 2017; 24: 1249-1257.

[60] Kaolawanich Y, Boonyasirinant T. Incremental prognostic value of aortic stiffness in addition to myocardial ischemia by cardiac magnetic resonance imaging. BMC Cardiovascular Disorders. 2020; 20: 287.

[61] Lee HS, Kim HL, Kim H, Hwang D, Choi HM, Oh SW, et al. Incremental Prognostic Value of Brachial-Ankle Pulse Wave Velocity to Single-Photon Emission Computed Tomography in Patients with Suspected Coronary Artery Disease. Journal of Atherosclerosis and Thrombosis. 2015; 22: 1040-1050.

[62] Hwang IC, Jin KN, Kim HL, Kim YN, Im MS, Lim WH, et al. Additional prognostic value of brachial-ankle pulse wave velocity to coronary computed tomography angiography in patients with suspected coronary artery disease. Atherosclerosis. 2018; 268: $127-137$.

[63] Kirigaya J, Iwahashi N, Tahakashi H, Minamimoto Y, Gohbara M, Abe T, et al. Impact of Cardio-Ankle Vascular Index on Long-Term Outcome in Patients with Acute Coronary Syndrome. Journal of Atherosclerosis and Thrombosis. 2020; 27: 657-668.

[64] Maruhashi T, Soga J, Fujimura N, Idei N, Mikami S, Iwamoto Y, et al. Endothelial Dysfunction, Increased Arterial Stiffness, and Cardiovascular Risk Prediction in Patients with Coronary Artery Disease: FMD-J (Flow-Mediated Dilation Japan) Study A. Journal of the American Heart Association. 2018; 7: e008588.

[65] Nagai K, Shibata S, Akishita M, Sudoh N, Obara T, Toba K, et $a l$. Efficacy of combined use of three non-invasive atherosclerosis tests to predict vascular events in the elderly; carotid intimamedia thickness, flow-mediated dilation of brachial artery and pulse wave velocity. Atherosclerosis. 2013; 231: 365-370.

[66] Sugamata W, Nakamura T, Uematsu M, Kitta Y, Fujioka D, Saito $\mathrm{Y}$, et al. Combined assessment of flow-mediated dilation of the brachial artery and brachial-ankle pulse wave velocity improves the prediction of future coronary events in patients with chronic coronary artery disease. Journal of Cardiology. 2014; 64: 179184.

[67] Narayan O, Davies JE, Hughes AD, Dart AM, Parker KH, Reid $\mathrm{C}$, et al. Central aortic reservoir-wave analysis improves prediction of cardiovascular events in elderly hypertensives. Hypertension. 2015; 65: 629-635.

[68] Cheng HM, Chuang SY, Wang JJ, Shih YT, Wang HN, Huang $\mathrm{CJ}$, et al. Prognostic significance of mechanical biomarkers derived from pulse wave analysis for predicting long-term cardiovascular mortality in two population-based cohorts. International Journal of Cardiology. 2016; 215: 388-395.

[69] Ohishi M, Tatara Y, Ito N, Takeya Y, Onishi M, Maekawa Y, et al. The combination of chronic kidney disease and increased arterial stiffness is a predictor for stroke and cardiovascular disease in hypertensive patients. Hypertension Research. 2011; 34: 1209_ 1215.

[70] Kim HL, Lim WH, Seo JB, Kim SH, Zo JH, Kim MA. Improved Prognostic Value in Predicting Long-Term Cardiovascular Events by a Combination of High-Sensitivity C-Reactive Protein and Brachial-Ankle Pulse Wave Velocity. Journal of Clinical Medicine. 2021; 10: 3291.

[71] Park HW, Kim HR, Kang MG, Kim K, Koh JS, Park JR, et al. Predictive value of the combination of brachial-ankle pulse wave velocity and ankle-brachial index for cardiovascular outcomes in patients with acute myocardial infarction. Coronary Artery Disease. 2020; 31: 157-165.

[72] Moon I, Jin KN, Kim HL, Suh HJ, Lim WH, Seo JB, et al. Association of arterial stiffness with aortic calcification and tortuosity. Medicine. 2019; 98: e16802. 